\title{
THE ESTIMATION OF THE ALKALINITY OF BLEACHING POWDER SOLUTIONS.
}

\author{
By KENNEDY J. P. ORTON, Ph.D., M.A., F.I.C., AND W. J. JONES., B.Sc.
} (Isaac Roberts Research Student).

(Read at the Meeting, June 9, 1909.)

The usual method of estimating the free alkali hydroxide in bleaching solutionsfor example, bleaching-powder solution - is that devised by Blattiner (Bull. Soc. Chim., 1891, 1, 116). It is based on the fact that alkaline bleaching solutions colour phenolphthalein. When the solution is titrated with standard sulphuric acid, the colour is discharged, not, however, by the excess of acid, but by the chlorine set free by the interaction of the hydrochloric and hypochlorous acids, when the excess of alkali has been neutralised. Addition of alkali does not in consequence restore the colour of the indicator. Owing to the extensive hydrolysis of hypochlorites, the destruction of the indicator tends to occur before the neutralisation of the alkali, and hence leads to an estimate of the latter which is below the actual value.

In addition to this possible objection, Blattner's procedure is not readily applicable to solid basic hypochlorites, such as are present in ordinary bleaching powder, or separate from bleaching powder solutions (Orton and Jones, J. Chem. Soc., 1909, 95, 751), inasmuch as it is not possible to dissolve these compounds entirely except in inconveniently large quantities of water.

We have devised a method which we find highly accurate for solutions of bleaching powder, and easily applied to the direct estimation of the calcium oxide or hydroxide in basic hypochlorites. In such bleaching solutions as those prepared from sodium hydroxide (or Eau de Javelle), which may contain some carbonate, this method gives the hydroxide and carbonate together, and does not directly distinguish between them.

The method is as follows: A known volume of approximately $\frac{\mathrm{N}}{\mathrm{i} 0}$ hydrochloric acid is placed in a Drechsel bubbler, and then a given volume of the bleaching powder solution is run in. A fairly rapid current of air, freed from dust, is now drawn through the liquid, the bubbler being carefully shielded from light. Aspiration for three-quarters of an hour suffices to free the liquid from chlorine, a fact which can be very easily tested by adding 1 drop of a 0.1 per cent. solution of methyl orange. The indicator is bleached if any chlorine remain. The excess of acid is then titrated with $\frac{\mathrm{N}}{10}$ sodium carbonate.

In the case of solid basic hypochlorite (or compounds of calcium chloride and hypochlorite) the procedure is identical, except that it is more convenient to introduce the solid into the bubbler before the acid.

The alkalinity of the solutions or solid is calculated from the following equations :

$$
\mathrm{Ca}(\mathrm{ClO})_{2}+4 \mathrm{HCl}=\mathrm{CaCl}_{2}+2 \mathrm{H}_{2} \mathrm{O}+2 \mathrm{Cl}_{2} \text {; and } \mathrm{Ca}(\mathrm{OH})_{2}+2 \mathrm{HCl}=\mathrm{CaCl}_{2}+2 \mathrm{H}_{2} \mathrm{O} \text {. }
$$

The thiosulphate or arsenite titre $\left(\frac{\mathrm{v}}{\mathrm{I} 0}\right)$ of the bleaching solution gives directly the volume of $\frac{N}{10}$ hydrochloric acid reacting with the hypochlorite. 
For this method to give trustworthy results, it is necessary that certain conditions hold. (1) No hypochlorous acid must pass over during the aspiration. It must entirely react with the hydrochloric acid. (2) All the chlorine must be evolved as gas, and none reduced to hydrochloric acid. (3) The hydrochloric acid must not react with chlorate at the dilutions used and at the ordinary temperature.

A number of separate experiments devised to test these requirements for accuracy have been made, with the result that all are found to hold rigidly under the conditions used.

The following analysis of a test solution, made up by passing chlorine into a standard solution of sodium hydroxide, demonstrates the accuracy of the method.

One hundred c.c. of the solution of sodium hydroxide contained 0.5476 gram.

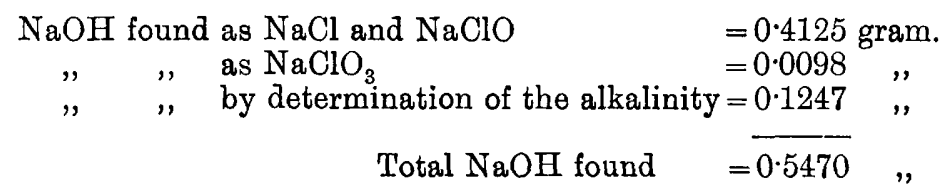

Estimations of the alkalinity of a large number of bleaching-powder solutions by this method have shown that such solutions are saturated with respect to calcium hydroxide, containing 1.6 to 1.7 grams per litre. As the concentration of the bleaching powder rises (active chlorine above $2 \mathrm{~N}$ ), the alkalinity falls, owing, doubtless, to the depression of the solubility of the calcium hydroxide by the high concentration of calcium chloride and calcium hypochlorite. Comparison of ours with Blattner's method shows, as was foreseen, that the latter gives a somewhat lower estimate of the alkalinity.

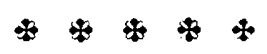

